\title{
Obstructive sleep apneas in relation to severity of cervical spinal cord injury
}

\author{
B Klefbeck ${ }^{1}$, M Sternhag ${ }^{2}, \mathrm{~J}_{\text {Weinberg }}{ }^{3}, \mathrm{R} \mathrm{Levi}^{4}, \mathrm{C} \mathrm{Hultling}^{4}$ and $\mathrm{J} \mathrm{Borg}^{2}$ \\ Departments of ${ }^{1}$ Physical Therapy, Karolinska Institute, Stockholm, ${ }^{2}$ Clinical Neuroscience, Karolinska Hospital, \\ Stockholm, ${ }^{3}$ Neurology, Huddinge Hospital, Huddinge, ${ }^{4}$ Spinalis SCI Research Unit, Karolinska Institute, Stockholm, \\ Sweden
}

\begin{abstract}
Thirty-three subjects (28 men, five women) with complete or incomplete cervical cord injury representing a wide range of neurological impairment were investigated with regard to the prevalence of Obstructive Sleep Apnea (OSA). The relation between OSA and neurological function, respiratory capacity, body mass index and symptoms associated with OSA were studied. Overnight sleep recordings employed combined oximetry and respiratory movement monitoring. Pulmonary function tests included static and dynamic spirometry, maximal static inspiratory and expiratory pressures at the mouth. The subjects answered a questionnaire concerning sleep quality and tiredness. The prevalence of OSA was $15 \%(5 / 33)$ in this nonobese cervical cord injury study population. Nine percent of the subjects $(3 / 33)$ fulfilled the criteria for obstructive sleep apnea syndrome, but daytime sleepiness or fatigue were also common in subjects without OSA. There was an inverse correlation between oxygen desaturation index and American Spinal Injury Association (ASIA) motor score in the subjects with complete injury, while there was no such correlation in the whole study group. There were significant correlations between maximal inspiratory and expiratory pressures and vital capacity and between ASIA motor score and vital capacity.
\end{abstract}

Keywords: ASIA motor score; oxygen desaturation; sleep apnea syndrome; sleep; tetraplegia

\section{Introduction}

Cervical spinal Cord Injury (CCI) might cause respiratory insufficiency due to respiratory muscle paresis. Lesions above the C5 level are most severe due to paresis of the diaphragm and might cause a reversible or persistent need for mechanical ventilation. ${ }^{1,2}$ In CCI patients with respiratory muscle paresis, but without need for assisted ventilation, an increased incidence of Obstructive Sleep Apneas (OSA), when compared to a non-injured population, has been reported. $^{3-6}$

OSA is characterised by sleep-related intermittent upper airway obstruction which may be associated with episodes of oxygen desaturations and sleep fragmentation. ${ }^{7}$ In obstructive sleep apnea syndrome this is combined with symptoms such as snoring, excessive daytime sleepiness and cardiovascular sequelae. ${ }^{8}$ The definition of respiratory events differs slightly in different studies. ${ }^{9-12}$ Young et $a l^{10}$ and Gislason et $a l^{11}$ define the apnea-hypopnea score as either a complete cessation of airflow lasting $10 \mathrm{~s}$ or more (apnea) or a reduction in respiratory airflow accompanied by a decrease of $4 \%$ or more in oxygen saturation (hypopnea). The apnea-hypopnea score is the average of apneas and hypopneas per hour of sleep.

Correspondence: B Klefbeck, Department of Physical Therapy, Karolinska Institute, Novum, S-141 57 Huddinge, Sweden
Using this score, Young et al found that 9\% of women and $24 \%$ of men had an apnea-hypopnea score of $\geqslant 5$. When they combined this with daytime hypersomnolence, they estimated the prevalence of obstructive sleep apnea syndrome to $2 \%$ among women and $4 \%$ among men. In a community-based study by Gislason et $a l^{11}$ the prevalence of obstructive sleep apnea syndrome was estimated at $1.3 \%$ among Swedish men.

Patients with cervical cord injuries often complain of sleeping problems and daytime sleepiness. ${ }^{13}$ McEvoy et $a l^{3}$ reported that nine of 40 patients with spinal cord injuries at C8 level and above had obstructive apneas and six of the 40 patients complained of daytime sleepiness which was directly related to the frequency of sleep arousals. Cahan et al $t^{5}$ noted that five of six quadriplegic patients with nighttime hypoxia had an increased daytime sleepiness compared to six of ten quadriplegic patients with nonhypoxia.

The pathophysiology of OSA is not fully understood. ${ }^{7}$ Obesity, ethanol, male gender, age and conditions that narrow the upper airway are considered strong risk factors in the non-injured population. ${ }^{14,15}$ In the CCI population, data concerning relations between sleep-disordered breathing and characteristics of the CCI is limited. An association between time spent below $90 \% \mathrm{SaO}_{2}$ and body mass 
index, level of injury and maximum expiratory pressure $^{6}$ as well as between sleep-disordered breathing and neck circumference and supine sleep posture ${ }^{3}$ have been reported.

The aims of this study were to further elucidate the prevalence of OSA and obstructive sleep apnea syndrome in subjects with CCI by use of a screening method for OSA and to study the relation to neurological function, respiratory capacity, body mass index and sleeping position.

\section{Subjects}

The criteria for participation were traumatic tetraplegia, one year or more post injury, motor injury level C4-T1 with complete or incomplete tetraplegia (A-D according to the American Spinal Injury Association (ASIA) impairment scale $)^{16,17} 20-60$ years of age, no pulmonary or cardiovascular disorders. Subjects with ventilatory treatment due to hypoventilation were excluded.

The subjects were invited to participate in the study as a complement to an annual routine follow up (May 1995 to November 1995) offered to all spinal cord injured subjects living in the Stockholm region. ${ }^{13}$ Of thirty-seven consecutive subjects, 33 subjects gave informed consent. There were 28 men and five women. Mean age was 37.9 (range 22-59) years and mean duration of injury was 13.9 (range $1-33$ ) years. Individual data in groups of complete and incomplete injury are given in Table 1.

\section{Methods}

Neurological examination for determination of completeness according to the ASIA impairment, sensory and motor scoring scales ${ }^{16,17}$ was performed.

Overnight sleep recording was performed in a single room in hospital. The sleeping position was repeatedly observed. However, the majority of the subjects slept all night in the same position because they were unable to turn. A simplified sleep apnea investigation consisting of combined ear oximetry (Ohmeda Biox 3740, Health Care, Louisville, USA) and respiratory and body movement monitoring (Static Charge Sensitive Bed) as described by Svanborg et $a l^{8}$ was performed. The body movement monitoring and oximetry data were collected by use of a pen-recorder (Graftec Thermal Array-corder WR 770, Graphitic Corporation, Yokohama, Japan) using slow paper speed $(10 \mathrm{~mm} / \mathrm{min})$ to clearly demonstrate changes in oxygen saturation $\left(\mathrm{SaO}_{2}\right)$ and respiration movement patterns. Oxygen Desaturation Index (ODI) was defined as the average number of oxygen desaturations of $4 \%$ or more per sleeping hour. ${ }^{8}$ Periods of obstructive apneas form a typical diamond-shaped pattern in the body movement monitoring (periodic respiration pattern), usually accompanied by repetitive oxygen desaturations. ${ }^{8}$ The recordings were analyzed manually. The number of significant desaturations and total time with periodic respiration in minutes were calculated. The nadir $\mathrm{SaO}_{2}$ value (the lowest value during the night) was also noted. Sleeping time was esimated from the patterns in the movement recording. Total sleeping time had to be $4 \mathrm{~h}$ or more, otherwise the examination was repeated. Criterion for pathologic recording, ie indicating OSA, was the combination of $\mathrm{ODI} \geqslant 6$ and $>45 \%$ periodic respiration time out of the total estimated sleeping time. ${ }^{8}$ If the subjects were unable to sleep in hospital, they were offered to sleep at home with the ApnoLog system (C-A Tegner Inc, Stockholm, Sweden) including pulse oximetry (Biox 3760), respiration and body movements (PVDF

Table 1 Characteristics of the subjects, nos 1-17 complete injuries, nos $18-33$ incomplete injuries

\begin{tabular}{|c|c|c|c|c|c|c|}
\hline & Subject & Gender & $\begin{array}{c}\text { Age } \\
\text { (years) }\end{array}$ & $\begin{array}{c}\text { Time } \\
\text { (years) }\end{array}$ & $\begin{array}{l}\text { Level o } \\
\text { (motor) }\end{array}$ & $\begin{array}{c}f \text { injury } \\
(\text { sens })\end{array}$ \\
\hline & 1 & Male & 26 & 1 & $\mathrm{C} 4$ & $\mathrm{C} 3$ \\
\hline & 2 & Male & 46 & 28 & C7 & C7 \\
\hline & 3 & Male & 59 & 30 & $\mathrm{C} 5 / \mathrm{C} 6$ & C3 \\
\hline & 4 & Female & 25 & 9 & C5 & $\mathrm{C} 4$ \\
\hline & 5 & Male & 36 & 20 & $\mathrm{C} 5$ & C6 \\
\hline & 6 & Female & 26 & 4 & C6 & C6 \\
\hline & 7 & Male & 25 & 6 & C6 & C5 \\
\hline & 8 & Male & 29 & 1 & $\mathrm{C} 6 / \mathrm{C} 5$ & $\mathrm{C} 5$ \\
\hline & 9 & Male & 46 & 32 & C7 & C6 \\
\hline & 10 & Male & 28 & 7 & C6 & C5 \\
\hline & 11 & Male & 30 & 27 & Th1 & C7 \\
\hline & 12 & Male & 32 & 15 & Th1 & C7 \\
\hline & 13 & Male & 24 & 3 & C6 & C5 \\
\hline & 14 & Male & 23 & 4 & C6 & $\mathrm{C} 4$ \\
\hline & 15 & Male & 22 & 2 & C5 & $\mathrm{C} 4$ \\
\hline & 16 & Female & 51 & 18 & C5 & C3 \\
\hline & 17 & Male & 28 & 8 & C4 & $\mathrm{C} 4$ \\
\hline & Mean & & 32.7 & 12.6 & & \\
\hline & $S D$ & & 11.0 & 11.0 & & \\
\hline & 18 & Male & 30 & 11 & C7 & C7 \\
\hline & 19 & Male & 24 & 2 & C6 & C6 \\
\hline & 20 & Male & 43 & 25 & C5 & $\mathrm{C} 4$ \\
\hline & 21 & Female & 39 & 4 & C5 & C4 \\
\hline & 22 & Male & 34 & 15 & C6 & $\mathrm{C} 4$ \\
\hline & 23 & Male & 45 & 3 & C8 & C7 \\
\hline & 24 & Male & 54 & 33 & * & C3 \\
\hline & 25 & Male & 53 & 4 & C5 & C3 \\
\hline & 26 & Male & 39 & 16 & C6 & C7 \\
\hline & 27 & Male & 43 & 24 & C5 & C5 \\
\hline & 28 & Male & 53 & 10 & C7 & C7 \\
\hline & 29 & Male & 50 & 33 & C7 & C7 \\
\hline & 30 & Male & 47 & 2 & C6 & $\mathrm{C} 4$ \\
\hline & 31 & Male & 58 & 33 & C4 & $\mathrm{C} 4$ \\
\hline & 32 & Female & 30 & 2 & C5 & Th5 \\
\hline & 33 & Male & 53 & 27 & C5 & Th7 \\
\hline & Mean & & 43.4 & 15.3 & & \\
\hline & $S D$ & & 10.1 & 12.2 & & \\
\hline Total & Mean & & 37.9 & 13.9 & & \\
\hline & $S D$ & & 11.8 & 11.5 & & \\
\hline
\end{tabular}

Time $($ years $)=$ time elapsed since injury, motor $=$ motor level of injury, sens $=$ sensory level of injury, $*=$ not possible to assess with ASIA, SD = standard deviation 
pressure sensor mattress). ${ }^{18}$ To make certain both methods were correlated, four subjects performed recordings both at home and in hospital. The results of the two methods were in good accordance even in estimating sleeping time.

A pulmonary function test with static and dynamic spirometry was performed and Maximal Inspiratory Pressure (MIP) and Maximal Expiratory Pressure (MEP) at the mouth (Precision Medical Ltd, UK) ${ }^{19-21}$ were measured. Body mass index $\left(\mathrm{kg} / \mathrm{m}^{2}\right)$ was calculated from the subject's weight in $\mathrm{kg}$ and length in meters. ${ }^{22}$ For the Swedish population, body mass index between 20.1 and 25.0 in men and 18.7 and 23.8 in women is considered normal. ${ }^{22}$

A detailed drug report including present use of antispastic and sedative drugs was obtained.

At the time of the sleep recordings, a questionnaire concerning sleep and tiredness during the last three months was distributed. The Basic Nordic Sleep Questionnaire 23,24 was used together with three questions from a Sleep and Health Questionnaire developed by Kump et al (Likert scale $1-6) .{ }^{25}$ In Kump's Questionnaire, the subject was asked to quantify the extent of her/his sleepiness, energy level, or performance impairment due to sleepiness.

Regression analyses were used to describe the relation between ODI, periodic respiration, ASIA motor score and pulmonary function data. Pearson's or Spearman's correlation coefficient was used to identify the relationship between variables. To analyse the answers from the questionnaire, they were subjectively divided into two groups (normal and pathologic) and a non-parametric test, MannWhitney, was used. $P<0.05$ was considered signficant.

\section{Results}

Sleep respiratory recordings

Thirty-one of the subjects performed the sleep recordings during one night. One patient had to do the sleep recording an extra night due to too short sleeping time during the first night. One further subject had sleeping difficulties in hospital and performed a sleep recording at home.

Mean sleeping time was 6.4 (SD 1.0) $\mathrm{h}$ and ranged $4.0-8.2 \mathrm{~h}$. Further individual sleep recording data are presented in Table 2. Mean awake $\mathrm{SaO}_{2}$ was $96.2 \%$ (SD 1.2) and ranged 94-98. Mean nadir $\mathrm{SaO}_{2}$ was $88.4 \%$ (SD 6.4) and ranged 69-95.

Median ODI was 1 and ODI ranged $0-29$. Median periodic respiration was $4 \%$ and ranged $0-89 \%$. When only subjects with ODI $>0 \quad(n=17)$ were considered, there was a statistically significant correlation between ODI and nadir $\mathrm{SaO}_{2} \quad\left(\mathrm{r}_{\mathrm{s}}=0.82\right.$, $P<0.05)$. When all subjects with $\mathrm{ODI}>0$ and periodic respiration $>45 \%$ were considered there were statistically significant correlations between ODI and periodic respiration $\left(\mathrm{r}_{\mathrm{s}}=0.50, P<0.05\right)$, as well as in the two subgroups with complete and incomplete injuries $\left(\mathrm{r}_{\mathrm{s}}=0.67, P<0.05\right.$ and $\mathrm{r}_{\mathrm{s}}=0.68$, $P<0.05)$. Five of the 33 subjects $(15 \%)$, all men, had ODI $>6$ and periodic breathing $>45 \%$ (values thus considered as pathological). ${ }^{8}$ Thus five of the 28 men $(18 \%)$ fulfilled the diagnostic criteria for OSA. Five additional subjects had pathological amounts of periodic breathing of clearly obstructive type (21$71 \%$ ). A sixth subject had ODI $=5$ and periodic respiration of $19 \%$. These six subjects are regarded as borderline cases. ${ }^{8}$

\section{ASIA motor score and sensory score and ODI/sleep respiratory recordings}

Mean ASIA motor score was 36.6 (SD 26.9) and ranged 0-90. Mean ASIA sensory score was for light touch 33.7 (SD 26.7) and ranged 8-110 and for pin prick 40.0 (SD 29.3) and ranged 8-110. Individual data are given in Table 2. There was no significant correlation between sleep respiratory pathology and motor or sensory scores. Of the five subjects with OSA, two had ASIA motor scores of 0 and 9 , while the other three subjects had ASIA motor scores of 43, 68 and 72. Two had complete injury and three had incomplete injury.

In the 17 subjects with complete injury (cf. Table 1) there was a significant $(r=0.48, P<0.05)$ correlation between ODI and ASIA motor score.

\section{Vital capacity, MIP, MEP and ODI/sleep respiratory recordings}

Spirometric pulmonary function tests were performed in 27 patients, and MIP and MEP were performed in 30 patients.

Mean Vital Capacity (VC) was 3.39 (SD 1.0) and ranged 1.21-4.85 litre. Mean forced expiratory volume during $1 \mathrm{~s}$ was 2.95 (SD 0.8) and ranged 1.15-3.90 litre. Mean MIP was 76.7 (SD 28.2) and ranged $17-131 \mathrm{~cm} \mathrm{H}_{2} \mathrm{O}$. Mean $\mathrm{MEP}$ was 70.4 (SD 31.7 ) and ranged $19-149 \mathrm{~cm} \mathrm{H}_{2} \mathrm{O}$. Individual data are given in Table 3 . There were no significant correlations between ODI or periodic respiration and any of the lung function tests. There were significant correlations between MIP and VC $(r=0.59, P<0.01)$, MEP and VC $(r=0.66, P<0.001)$ and between ASIA motor score and VC $(r=0.60, P<0.01)$.

\section{Body mass index, age and ODI/sleep respiratory recordings}

Mean Body Mass Index (BMI) was 21.2 (SD 3.8) and ranged $13.6-30.0 \mathrm{~kg} / \mathrm{m}^{2}$. It should be noted that none of the subjects was morbidly obese $(\mathrm{BMI}>30)$. Individual data are given in Table 4. Three men had $\mathrm{BMI}>25$ and one female had $\mathrm{BMI}=30.0$, none of these had ODI $>6$. The age of the subjects ranged from 22-59 years. There were no significant correlations between ODI or periodic respiration and BMI, age or time elapsed since injury. 
Sleeping position and ODI/sleep respiratory recordings Twenty-seven of 33 subjects slept in the supine position and only five of them alternated between the supine and lateral positions or between the prone and supine positions. Six subjects spent all night in the lateral position. Individual data are given in Table 4. Of five subjects with OSA, four spent all night in the supine position and the fifth subject spent part of the night in the supine position. Of the six subjects with borderline results, four slept all night in the supine position, one altered between the lateral and supine position and the sixth subject slept in the lateral position. None of the 22 subjects slept in the elevated position.

Table 2 Individual sleep breathing data and motor and sensory scores, subjects nos $1-17$ complete injuries, subject nos $18-33$ incomplete injures

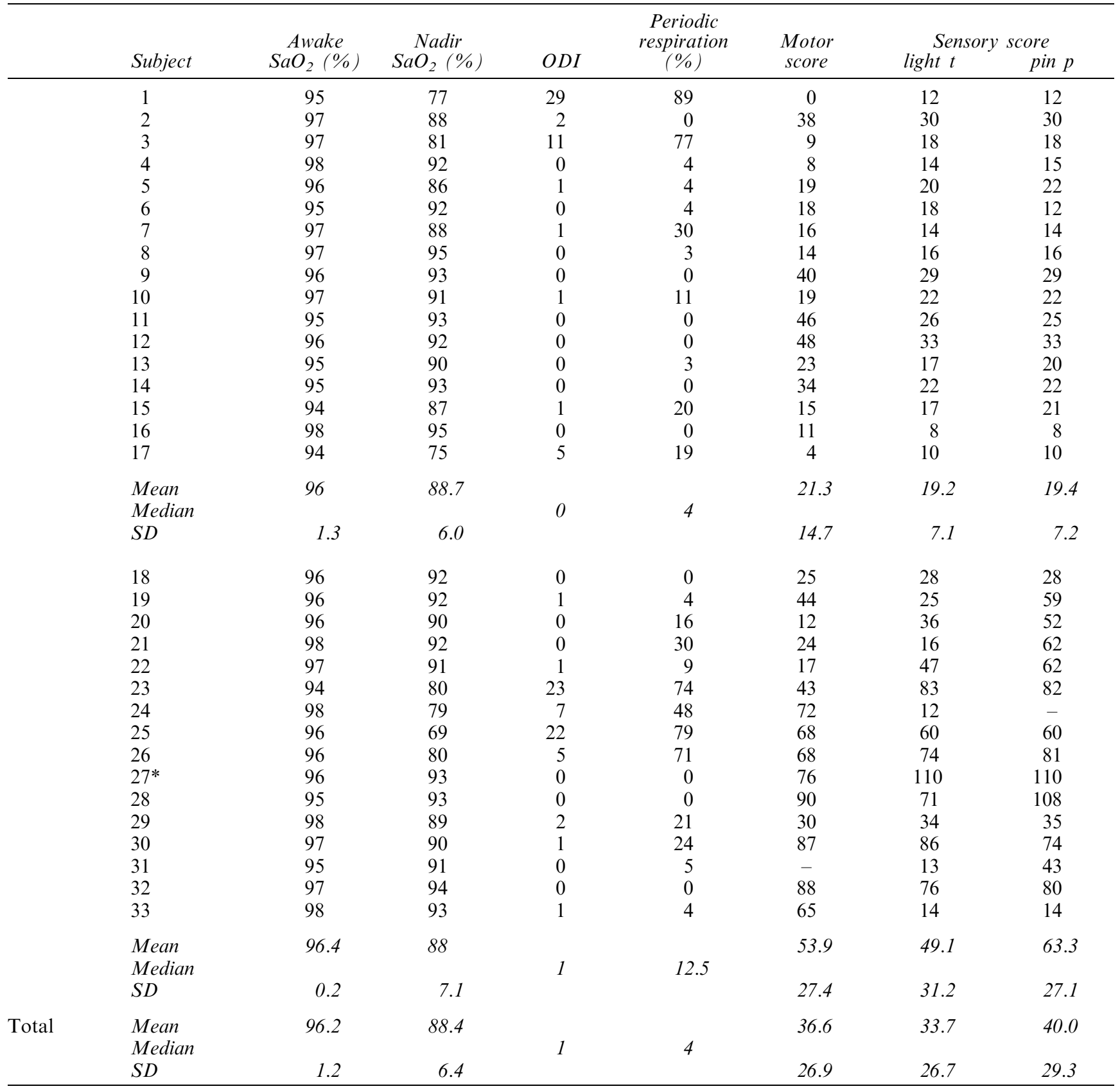

Awake $\mathrm{SaO}_{2}=$ oxygen saturation at start of the registration, Nadir $\mathrm{SaO}_{2}=$ lowest registered saturation, ODI $=$ total number of desaturations divided by the sleeping time in hours, light $\mathrm{t}=$ light touch, pin $\mathrm{p}=$ pin prick, $*=$ home sleep recording, $-=$ missing value, $\mathrm{SD}=$ standard deviation 
Drugs and ODI/sleep respiratory recordings

Eleven subjects used baclofen $(70-125 \mathrm{mg})$ and diazepam $(1.25-5 \mathrm{mg})$ for reducing spacticity. One subject with OSA and three borderline cases used baclofen. A routine clinical evaluation revealed no history of alcohol or psychotropic drug abuse. Individual data are presented in Table 4.
Questionnaire, snoring and ODI/sleep respiratory recordings

Three of the five subjects with ODI $>6$ and seven of the 28 subjects with ODI $<6$ reported excessive tiredness and sleep disturbances. Three of $33(9 \%)$ subjects therefore fulfilled the criteria for obstructive sleep apnea syndrome. Three subjects with ODI $>6$

Table 3 ODI and data from pulmonary function tests, subjects nos 1-17 complete injuries, subjects nos $18-33$ incomplete injuries

\begin{tabular}{|c|c|c|c|c|c|c|c|c|c|}
\hline & Subject & $O D I$ & (litre) & pred & $\begin{array}{l}F E V_{1,0} \\
\text { (litre } / s \text { ) }\end{array}$ & $\begin{array}{c}F I V_{1,0} \\
\text { (litre/s) }\end{array}$ & $\begin{array}{c}\text { FRC } \\
\text { (litre) }\end{array}$ & $\begin{array}{c}M I P \\
\left(\mathrm{~cm} \mathrm{H} \mathrm{H}_{2} \mathrm{O}\right)\end{array}$ & $\begin{array}{c}M E P \\
\left(\mathrm{~cm} \mathrm{H} \mathrm{H}_{2} \mathrm{O}\right)\end{array}$ \\
\hline & 1 & 29 & 1.21 & 20 & 1.20 & - & 3.96 & 48 & 19 \\
\hline & 2 & 2 & 3.78 & 75 & 3.75 & 3.52 & 5.24 & 68 & 63 \\
\hline & 3 & 11 & - & & - & - & - & 70 & 39 \\
\hline & 4 & 0 & 1.22 & 29 & 1.15 & 1.02 & 1.86 & 42 & 25 \\
\hline & 5 & 1 & 3.00 & 53 & 2.46 & 2.62 & 3.10 & 51 & 38 \\
\hline & 6 & 0 & 2.92 & 74 & 2.67 & 2.68 & 2.70 & 80 & 51 \\
\hline & 7 & 1 & 3.93 & 64 & 3.64 & 3.31 & 4.06 & 58 & 32 \\
\hline & 8 & 0 & 2.92 & 51 & 2.70 & 2.42 & - & 74 & 63 \\
\hline & 9 & 0 & - & & - & - & - & - & - \\
\hline & 10 & 1 & 3.81 & 66 & 3.23 & 3.20 & 4.18 & 71 & 71 \\
\hline & 11 & 0 & - & & - & - & - & 131 & 109 \\
\hline & 12 & 0 & 4.21 & 75 & - & - & 2.52 & 129 & 103 \\
\hline & 13 & 0 & 4.42 & 72 & 3.75 & - & 3.88 & 107 & 105 \\
\hline & 14 & 0 & - & & - & - & - & 56 & 58 \\
\hline & 15 & 1 & 2.66 & 47 & 2.43 & 2.42 & 3.58 & 62 & 32 \\
\hline & 16 & 0 & 1.28 & 36 & 1.19 & - & - & - & - \\
\hline & 17 & 5 & 2.20 & 37 & - & - & - & 41 & 48 \\
\hline & Mean & 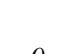 & 2.89 & 53.8 & 2.56 & 2.64 & 3.5 & 72.5 & 57.1 \\
\hline & $\begin{array}{l}\text { Median } \\
S D\end{array}$ & 0 & 1.1 & 18.9 & 1.0 & 0.8 & 1.0 & 28.6 & 29.2 \\
\hline & 18 & 0 & - & & - & - & - & 66 & 67 \\
\hline & 19 & 1 & 4.13 & 67 & 3.68 & 3.91 & 3.85 & 123 & 97 \\
\hline & 20 & 0 & 3.74 & 68 & 3.23 & 3.01 & 3.48 & 114 & 74 \\
\hline & 21 & 0 & 3.11 & 92 & 2.86 & 2.86 & 3.29 & 47 & 44 \\
\hline & 22 & 1 & 3.31 & 66 & 3.10 & 2.99 & 3.94 & 88 & 65 \\
\hline & 23 & 23 & 4.85 & 96 & 3.80 & 4.47 & 3.94 & 85 & 80 \\
\hline & 24 & 7 & 3.96 & 81 & 3.25 & 3.66 & 3.41 & - & - \\
\hline & 25 & 22 & 4.57 & 93 & 3.90 & 3.83 & 4.07 & 101 & 104 \\
\hline & 26 & 4 & 4.06 & 84 & 3.32 & 3.69 & 2.52 & 100 & 108 \\
\hline & 27 & 0 & 3.83 & 72 & 3.40 & 3.18 & 3.76 & 55 & 78 \\
\hline & 28 & 0 & 3.34 & 74 & 2.69 & 2.94 & 2.66 & 73 & 149 \\
\hline & 29 & 2 & 3.32 & 62 & 3.11 & 2.97 & 4.29 & 92 & 75 \\
\hline & 30 & 1 & - & & - & - & - & 109 & 118 \\
\hline & 31 & 0 & 3.05 & 79 & 2.04 & 1.54 & 2.87 & 17 & 30 \\
\hline & 32 & 0 & 3.95 & 92 & 3.32 & 3.75 & 2.36 & 81 & 78 \\
\hline & 33 & 1 & 4.69 & 107 & 3.85 & 3.65 & 4.31 & 63 & 88 \\
\hline & Mean & & 3.85 & 80.9 & 3.3 & 3.32 & 3.48 & 80.9 & 83.7 \\
\hline & Median & 1 & & & & & & & \\
\hline & $S D$ & & 0.6 & 13.5 & 0.5 & 0.7 & 0.7 & 28.2 & 29.2 \\
\hline Total & Mean & & 3.39 & 67.9 & 2.95 & 3.07 & 3.49 & 76.7 & 70.4 \\
\hline & $S D$ & & 1.0 & 21.2 & 0.8 & 0.8 & 0.8 & 28.2 & 31.7 \\
\hline
\end{tabular}

$\mathrm{ODI}=$ total number of desaturations divided by the sleeping time in hours, $\mathrm{VC}=\mathrm{Vital}$ capacity, pred $=$ percent of predicted normal, $\mathrm{FEV}_{1,0}=$ Forced expiratory volume during $1 \mathrm{~s}, \mathrm{FIV}_{1,0}=$ Forced inspiratory volume during $1 \mathrm{~s}, \mathrm{FRC}=\mathrm{Functional}$ residual capacity, $\mathrm{MIP}=$ Maximal inspiratory pressure, $\mathrm{MEP}=$ Maximal expiratory pressure, $-=$ missing values, $\mathrm{SD}=\mathrm{standard}$ deviation 
and four subjects with ODI $<6$ reported of snoring. Individual data of symptoms and snoring are presented in Table 4. There were no statistically significant correlations between ODI and data from the questionnaire.

\section{Discussion}

The study group can be considered as unselected and representative for the cervical cord injured subjects in the Stockholm area as the subjects were recruited

Table 4 ODI in relation to BMI, sleeping position, symptoms, snoring and used muscle relaxant, subjects nos $1-17$ complete injuries, subjects nos $18-33$ incomplete injuries

\begin{tabular}{|c|c|c|c|c|c|c|c|c|}
\hline & Subject & $O D I$ & $\begin{array}{c}B M I \\
\left(\mathrm{~kg} / \mathrm{m}^{2}\right)\end{array}$ & $\begin{array}{l}\text { Sleeping } \\
\text { position }\end{array}$ & Symptom & Snoring & $\begin{array}{l}\text { Muscle } \\
\text { relaxant }\end{array}$ & Dosage \\
\hline & 1 & 29 & 14.9 & sup & + & + & & \\
\hline & 2 & 2 & 20.1 & prone/sup & & & & \\
\hline & 3 & 11 & 22.5 & sup & + & + & & \\
\hline & 4 & 0 & 15.5 & lat & & & & \\
\hline & 5 & 1 & 23.4 & sup & & & bac & $125 \mathrm{mg}$ \\
\hline & 6 & 0 & 23.7 & lat & & & & \\
\hline & 7 & 1 & 16.2 & sup & & & bac & $75 \mathrm{mg}$ \\
\hline & 8 & 0 & 19.1 & sup & & & bac & $30 \mathrm{mg}$ \\
\hline & 9 & 0 & 22.0 & lat & + & + & bac & $75 \mathrm{mg}$ \\
\hline & 10 & 1 & 14.8 & sup & & & & \\
\hline & 11 & 0 & 21.6 & lat & + & & & \\
\hline & 12 & 0 & 17.6 & lat & & & & \\
\hline & 13 & 0 & 19.9 & sup & & & & \\
\hline & 14 & 0 & 18.6 & sup & & & bac & $75 \mathrm{mg}$ \\
\hline & 15 & 1 & 20.1 & sup & + & & & \\
\hline & 16 & 0 & 16.9 & sup & & & & \\
\hline & 17 & 5 & 25.2 & lat/sup & & & bac & $100 \mathrm{mg}$ \\
\hline & Mean & & 19.5 & & & & & \\
\hline & Median & 0 & & & & & & \\
\hline & $S D$ & & 3.2 & & & & & \\
\hline & 18 & 0 & 23.0 & sup & & & & \\
\hline & 19 & 1 & 20.5 & sup & & & & \\
\hline & 20 & 0 & 24.6 & sup & & & dia & $5 \mathrm{mg}$ \\
\hline & 21 & 0 & 19.6 & sup & & & & \\
\hline & 22 & 1 & 21.6 & sup & + & & $\mathrm{bac}+\mathrm{dia}$ & $70+1.25 \mathrm{mg}$ \\
\hline & 23 & 23 & 22.5 & sup & + & + & & \\
\hline & 24 & 7 & 23.1 & lat/sup & & & & \\
\hline & 25 & 22 & 21.1 & sup & & & bac & $75 \mathrm{mg}$ \\
\hline & 26 & 4 & 23.4 & sup & & + & & \\
\hline & 27 & 0 & 23.5 & sup & & & & \\
\hline & 28 & 0 & 27.7 & lat/sup & & & & \\
\hline & 29 & 2 & 13.6 & lat & & + & & \\
\hline & 30 & 1 & 25.6 & sup & + & & bac & $125 \mathrm{mg}$ \\
\hline & 31 & 0 & 23.0 & lat/sup & + & + & dia & $5 \mathrm{mg}$ \\
\hline & 32 & 0 & 30.0 & sup & + & & & \\
\hline & 33 & 1 & 24.9 & sup & & & & \\
\hline & Mean & & 23.0 & & & & & \\
\hline & Median & 1 & & & & & & \\
\hline & $S D$ & & 3.6 & & & & & \\
\hline Total & Mean & & 21.2 & & & & & \\
\hline & Median & 1 & & & & & & \\
\hline & $S D$ & & 3.8 & & & & & \\
\hline
\end{tabular}

$\mathrm{ODI}=$ total number of desaturations divided by the sleeping time in hours, BMI $=$ Body Mass Index, sup $=$ supine, lat $=$ lateral, $+=$ symptom present as excessive tiredness and sleep disturbances or snoring, $b a c=$ baclofen, dia $=$ diazepam, Dosage $=$ dosage of muscle relaxant, $\mathrm{SD}=$ standard deviation 
consecutively from the yearly routine follow-up. There were 28 men $(85 \%)$ in this study, as compared to $81 \%$ men in an inventory of the spinal cord injured population in the same region in Sweden. ${ }^{13}$ Subjects included had complete or incomplete injuries at different cervical levels representing a wide spectrum of neurological and respiratory dysfunction.

In the present study the prevalence of cases who fulfilled the laboratory criteria for OSA was $15 \%$ $(5 / 33)$, that is within the same order as in a community based study by Young et $a l^{10}$ of non-injured subjects where the prevalence of OSA was $9 \%$ in women and $24 \%$ in men. However, when comparing this data two points must be considered. First, Young's as well as other studies of non injured populations include obese subjects known to have an increased risk for OSA. ${ }^{12,14,26,27}$ In our study there were no morbidly obese subjects. Four subjects had BMI above normal range, corresponding to overweight for three men and obesity for one woman, ${ }^{22}$ and those four all had normal nocturnal respiration. In a population-based survey of non-injured subjects by Kripke et $a l^{27}$ the prevalence of ODI $\geqslant 20$ in subjects with $\mathrm{BMI}<29$ was $3 \%$, while the corresponding prevalence in our study was $9 \%$. Thus, the prevalence of OSA seems to be higher in non-obese CCI-subjects than in non-obese, non-injured subjects. Further, in our study there were six additional border-line cases with high amounts of obstructive breathing but virtually normal oximetry. Some of these might have more than $10 \mathrm{~s}$ cessation of airflow and thus fulfil the criteria for OSA according to Young et al. ${ }^{10}$

There was a significant negative correlation between the degree of obstructive respiration and ASIA motor score in the subpopulation of CCI subjects with more severe injuries. Previous studies also indicate that the prevalence of OSA increases with more severe injuries (cf. further discussion below).

There was no correlation between ODI and data from the questionnaire. Ten subjects reported symptoms in accordance with obstructive sleep apnea syndrome. Three of them had OSA and reported sleep disturbances and excessive daytime tiredness/ sleepiness and snoring and thus fulfilled the criteria for obstructive sleep apnea syndrome, thus the estimated prevalence of obstructive sleep apnea syndrome in the study population was $9 \%(3 / 33)$, that is higher than the estimated $1.3 \%$ in a Swedish prevalence study ${ }^{11}$ of non injured subjects. Seven subjects reported sleep disturbances and excessive tiredness, but had normal sleep recordings, indicating that other causes of disturbed sleep are common in this group.

The observed prevalence of OSA in the present study was lower than reported in previous studies of CCI subjects. ${ }^{3-6}$ This might be due to different methods and patient selection. The method used for screening of OSA and the criteria used for classification of OSA in the present study are well established and only slightly different from those in some of the previous studies $^{3-5}$ and should have only marginal, if any, significance for the differing results. However, previous studies have included subjects with a higher mean age and/or more severe injury. The observed prevalence of OSA was $22 \%$ in a study by McEvoy et $a l^{3}$ in CCI-subjects with Frankel grades $\mathrm{A}-\mathrm{C}$ and a mean vital capacity of $54.3 \%$ of predicted normal, $45 \%$ in a study by Short et $a l^{4}$ in CCI-subjects who had a mean age of 58.5 years, a median vital capacity of 2.47 litres and Frankel grades $\mathrm{A}-\mathrm{C}$ and $38 \%$ in a study by Cahan et $a l^{5}$ in subjects with a mean age of 48 years. Flavell ${ }^{6}$ reported severe nocturnal desaturations in $30 \%$ in subjects with injury at C4-C6 level with Frankel grades $\mathrm{A}-\mathrm{B}$ and a mean vital capacity of $45.7 \%$ of predicted normal. Thus, we suggest that higher age and more severe injury might explain the higher prevalence of OSA observed in these previous studies. This is also in agreement with our observation of an inverse correlation between ODI and ASIA motor score in the subjects with complete injury in the present study and thus in accordance with previous findings where the level of injury or vital capacity was correlated to OSA. ${ }^{5,6}$

It has been shown that normal subjects may exhibit OSA after topical oropharyngeal anesthesia ${ }^{28}$ and that the temperature sensitivity is selectively impaired in the oropharynx of patients with obstructive sleep apnea syndrome. ${ }^{29}$ The CCI subjects had no sensory involvement of the oropharynx and there was no significant correlation between ODI or periodic breathing and degree of sensory loss, as defined in the ASIA sensory score. This indicates that the sensory disturbance due to spinal cord injury has no significance for OSA.

There was a significant correlation between ASIA motor score and VC, as expected, as well as between VC and MEP and between VC and MIP in the present study. The significant correlation seen between VC and MIP is in contrast to the study of Roth et $a l^{30}$ who did not find any correlation between these parameters in 52 patients with complete C4-Th6 spinal cord injury. The discrepancy might be explained by a greater range of motor functions in the present study, which included subjects with both complete and incomplete injuries.

Of the subjects with OSA four of five spent all night supine, one subject was supine part of the night, and had ODI $=7$. However, the majority 22,33 of the tetraplegic subjects in the present study had difficulties in changing sleeping position during the night and thus spent all night in the supine position. Previous studies of non-injured subjects indicate that the supine position increases the risk for OSA ${ }^{31}$ while the lateral position reduces the risk. ${ }^{32}$ Even if our data does not permit any conclusion, it is in accordance with these findings.

Eleven of 33 subjects in the present study were using muscle relaxants but only one of them was classified as OSA and three as borderline cases. In the study of Short et $a l^{4}$ six of 22 patients with more than five desaturations per hour were using baclofen. It has 
been shown that a single dose of $25 \mathrm{mg}$ baclofen alters the sleep architecture and produces a small reduction in mean sleep oxygen saturation although it does not significantly increase sleep-disordered breathing. ${ }^{33}$ Thus, baclofen might be a risk factor for OSA but our data indicates that moderate doses are not a major risk factor.

\section{Conclusion}

The prevalence of OSA in CCI subjects with a wide range of motor loss (ASIA motor score 0-90) and respiratory impairment (VC $1.21-4.85$ litre) was 15\% and higher than in a corresponding, non-obese, noninjured population. There was an inverse relation between ODI and ASIA motor score in the subgroup with complete injury. The prevalence of obstructive sleep apnea syndrome was $9 \%$, which is higher than in the estimated prevalence in Swedish non-injured subjects. Symptoms associated with OSA were not related to the results of the respiratory recordings and are thus not appropriate for predicting OSA in this patient group.

\section{Acknowledgements}

This study was supported by grants from The Spinalis Foundation, Karolinska Institute and the Swedish Association for Traffic and Polio Disabled. Eva Svanborg MD, $\mathrm{PhD}$ is acknowledged for her valuable comments.

\section{References}

1 Carter RE. Respiratory aspects of spinal cord injury management. Paraplegia 1987; 25: 262-266.

2 Fuhrer MJ et al. Postdischarge outcomes for ventilatordependent quadriplegics. Arch Phys Med Rehabil 1987; 68: $353-356$.

3 McEvoy DR et al. Sleep apnoea in patients with quadriplegia. Thorax 1995; 50: 613-619.

4 Short DJ, Stradling JR, Williams SJ. Prevalence of sleep apnoea in patients over 40 years of age with spinal cord lesions. J Neurol Neurosurg Psychiatry 1992; 55: 1032 - 1036.

5 Cahan $\mathrm{C}$ et al. Arterial oxygen saturation over time and sleep studies in quadriplegic patients. Paraplegia 1993; 31: $172-179$.

6 Flavell $\mathrm{H}$ et al. Hypoxia episodes during sleep in high tetraplegia. Arch Phys Med Rehabil 1992; 73: 623-627.

7 Strohl KP, Redline S. Recognition of obstructive sleep apnea. Am J Respir Crit Care Med 1996; 154: 279-289.

8 Svanborg E, Larsson H, Carlsson-Nordlander B, Pirskanen R. A limited diagnostic investigation for obstructive sleep apnea syndrome. Oximetry and static charge sensitive bed. Chest 1990; 98: $1341-1345$.

9 Lavie P. Incidence of sleep apnea in a presumably healthy working population: A significant relationship with excessive daytime sleepiness. Sleep 1983; 6: $312-318$.

10 Young $\mathrm{T}$ et al. The occurance of sleep-disordered breathing among middle-aged adults. $N$ Engl J Med 1993; 328: 1230 - 1235.
11 Gislason $\mathrm{T}$ et al. Prevalence of sleep apnea syndrome among Swedish men: an epidemiological study. J Clin Epidemiol 1998; 41: $571-576$.

12 Strandling JR, Crosby JH. Predictors and prevalence of obstructive sleep apnoea and snoring in 1001 middle aged men. Thorax 1991; 46: 85-90.

13 Levi R, Hultling C, Nash MS, Seiger A. The Stockholm spinal injury study: 1. Medical problems in regional SCI population. Paraplegia 1995; 33: $308-315$.

14 Block A, Boysen PG, Wynne JW, Hunt LA. Sleep apnea, hypopnea and oxygen desaturation in normal subjects. $N$ Engl $J$ Med 1979; 300: $513-517$.

15 Deegan PC, McNicholas WT. Pathophysiology of obstructive sleep apnoea. Eur Respir J 1995; 8: 1161 - 1178.

16 Ditunno JF, Young W, Donovan WH, Creasey G. The international standards booklet for neurological and functional classification of spinal cord injury. Paraplegia 1994; 32: 70-80.

17 El Masry WS et al. Validation of the American Spinal Injury Association (ASIA) Motor Score and the National Acute Spinal Cord Injury Study (NASCIS) Motor Score. Spine 1996; 21: 614619.

18 Svanborg E, Páal T, Möller J. Apno-Log - a portable monitoring system for home recordings of obstructive sleep apneas. Sleep Res 1992; 1: 225.

19 Black LF, Hyatt RE. Maximal static respiratory pressures in generalized neuromuscular disease. Am Rev Respir Dis 1971; 103: $641-650$.

20 Black LF, Hyatt RE. Maximal respiratory pressures: Normal values and relationship to age and sex. Am Rev Respir Dis 1969; 99: $696-702$.

21 Hamnegård C-H et al. Portable measurement of maximum mouth pressures. Eur Respir J 1994; 7: 398-401.

22 Kuskowska WA, Rössner S. Body mass distribution of a representative adult population in Sweden. Diab Research Clinical Practice 1990; 10: S37-S41.

23 Gisalson T et al. Basic Nordic Sleep Questionnaire. Scandinavian Society for Sleep Research. 1988.

24 Biering-Sörensen F, Biering-Sörensen M, Hilden J. Reproducibility of Nordic Sleep Questionnaire in spinal cord injured. Paraplegia 1994; 32: 780-786.

25 Kump K et al. Assessment of the validity and utility of a sleepsymptom questionnaire. Am J Respir Crit Care Med 1994; 150: $735-741$.

26 Vgontzas AN et al. Sleep apnea and sleep disruption in obese patients. Arch Intern Med 1994; 154: 1705-1711.

27 Kripke DF et al. Prevalence of sleep-disordered breathing in ages 40-64 years: A population-based survey. Sleep 1997; 20: $65-76$.

28 McNicholas W et al. Upper airway obstruction during sleep in normal subjects after selective topical oropharyngeal anesthesia. Am Rev Respir Dis 1987; 135: 1316-1319.

29 Larsson $\mathrm{H}$ et al. Temperature thresholds in the oropharynx of patients with obstructive sleep apnea syndrome. Am Rev Respir Dis 1992; 146: 1246 - 1249

30 Roth EJ et al. Pulmonary function testing in spinal cord injury: correlation with vital capacity. Paraplegia 1995; 33: $451-457$.

31 Svanborg E et al. Hur vanlig är positionskänslighet vid obstruktivt sömnapnésyndrom? Abstract Läkarstämman, Stockholm 1995.

32 McKenzie Neill A, Angus SM, Sajkov D, McEvoy RD. Effects of sleep posture on upper airway stability in patients with obstructive sleep apnea. Am J Respir Crit Care Med 1997; 155: $199-204$.

33 Finnimore AJ, Roebuck M, Sajkov D, McEvoy RD. The effects of the GABA agonist, baclofen, on sleep and breathing. Eur Respir J 1995; 8: 230-234. 